Linda Jo Rice MD, Mary Ann Pudimat MD, Raafat S. Hannallah MD

\title{
Timing of caudal block placement in relation to surgery does not affect duration of postoperative analgesia in paediatric ambula- tory patients
}

\begin{abstract}
The purpose of this study was to determine if the timing of caudal block placement in relation to surgery affected either the duration of postoperative pain relief or the discharge time in children undergoing brief ambulatory surgical procedures. Forty ASA physical status I or II children ages 18 mo to II yr were randomly assigned to one of two groups. Group I patients received a caudal block with $0.5 \mathrm{ml} \cdot \mathrm{kg}^{-1}$ of bupivacaine 0.25 per cent following the induction of anaesthesia but before the onset of surgery. Group 2 patients received a similar block at the completion of surgery but before emergence from general anaesthesia. An experienced observer, who was not aware of the timing of block placement, observed all patients from arrival to the post-anaesthetic recovery room until discharge from the ambulatory surgery unit. Pain was assessed at five-minute intervals using an Objective Pain Scale. No statistically significant differences were noted between Group / and Group 2 patients with regard to their postoperative pain/discomfort scores, the need for postoperative narcotic analgesia, or the time required for either group to meet standard discharge
\end{abstract}

\section{Key words}

ANAESTHESIA: paediatric;

ANAESTHETIC TECHNIQUES: caudal;

PAIN: postoperative;

SURGERY: ambulatory.

Departments of Anesthesiology and Pediatrics, Children's National Medical Center and the George Washington University School of Medicine, Washington, D.C.

Address correspondence 10: Dr. Linda Jo Rice, Department of Anesthesiology, Children's National Medical Center,

111 Michigan Avenue, NW, Washington, D.C. 20010.

Presented in part at the annual meeting of the American

Society of Anesthesiologists, San Francisco, California, October 1988. criteria. It is concluded that the duration of postoperative analgesia is not impaired by placing the caudal block prior 10 the start of a brief surgical procedure.

Faire un bloc caudal avant plutôt qu' après une courte interven. tion chirurgicale en externe importe t'il sur la durée de l'analgésie et le moment du congé? Nous avons randomisés 40 enfants de 18 mois à 11 ans et de classe ASA $I$ ou $I I$ en deux groupes. Sous anesthésie générale, nous faisions un bloc caudal avec $0,5 \mathrm{ml} \cdot \mathrm{kg}^{-1}$ de bupivacaïne a 0,25 pour cem juste avam le début de la chirurgie dans le groupe l et juste apres la fin celle-ci dans le groupe II. De leur arrivée en salle de réveil jusqu'à leur départ pour la maison, un observareur indépendant notait au cinq minutes l' intensite de la douleur des enfants sur une échelle objective. Nous n'avons observé aucune différence statistique entre les groupes quant l' intensité des douleurs, à la quantité de morphinique necessaire pour les soulager non plus qu'au temps requis pour rencontrer les critères habituels de congé. Il semble donc que la durée de l'analgésie post-opératoire soit adéquate même si on fait le bloc caudal avant plutôt qu après une brève intervention chirurgicale.

The scope of outpatient surgery for infants and children is continuously expanding to include more surgical procedures. Postoperative pain with a concomitant high incidence of nausea and vomiting may be associated with these operations. ${ }^{1,2}$ Previous studies have documented that caudal blocks performed at the completion of hernia repair, orchiopexy and hydrocelectomy produce effective postoperative analgesia. ${ }^{3,4}$ However, some anaesthetists prefer to place caudal blocks after the induction of general anaesthesia but prior to the start of surgery, in order to obtain both adjunct intraoperative anaesthesia as well as postoperative analgesia. ${ }^{5}$ The purpose of this study was to determine if the timing of caudal block placement in 
TABLE I Paediatric objective pain scale ${ }^{3}$

\begin{tabular}{|c|c|c|c|}
\hline & 0 & $I$ & 2 \\
\hline Blood pressure & $B P \pm 10 \%$ preop & $\mathrm{BP}>20 \%$ preop & $\mathrm{BP}>30 \%$ preop \\
\hline Crying & Not crying & Crying but responding to TLC* & Crying but not responding to TLC* \\
\hline Movement & None & Restless & Thrashing \\
\hline Anxiety & Patient asleep or calm & Mild & Hysterical \\
\hline Posture & No special posture & Flexing leg and thigh & Holding groin \\
\hline
\end{tabular}

relation to surgery affected either the duration of postoperative pain relief or discharge time in children undergoing brief ambulatory surgical procedures.

\section{Methods}

Institutional approval and informed parental consent were obtained for 40 ASA physical status I or II children, ages $18 \mathrm{mo}$ to $11 \mathrm{yr}$, undergoing hernia repair, orchiopexy or hydrocelectomy on an ambulatory basis. Anaesthesia was induced with inhalation of nitrous oxide, halothane and oxygen and maintained using nitrous oxide 70 per cent and 1.0 MAC halothane (inspired) via face mask in all cases. Children were randomly assigned to one of two groups. Group 1 patients received a caudal block with 0.5 $\mathrm{ml} \cdot \mathrm{kg}^{-1}$ of bupivacaine 0.25 per cent following the induction of general anaesthesia but before the onset of surgery, while Group 2 patients received similar blocks following the completion of surgery but prior to emergence from anaesthesia. All patients were monitored in the post-anaesthetic recovery room (PARR) by an experienced observer who was blinded to the timing of block placement. In order to prevent the observer from guessing the group assignment of patients by their rate of recovery, the intraoperative inspired halothane concentration was maintained at 1.0 MAC in all patients to achieve a uniform rate of emergence from anaesthesia. All intraoperative anaesthetic records were kept sealed at the bedside in the PARR.

The degree of recovery from general anaesthesia was assessed using a modified Aldrete score. ${ }^{6}$ Pain was assessed upon arrival in the PARR and at five minute intervals, using a previously described Objective Pain $\mathrm{Scale}^{3}$ in which pain and/or discomfort are correlated with posturing, movement, crying, blood pressure elevation, and anxiety on a scale of $0-2$ for each of the five categories (Table l). Intravenous fentanyl $1-2 \mu \mathrm{g} \cdot \mathrm{kg}^{-1}$ was administered to any patient who achieved a pain score of six or more for two consecutive five-minute periods of observation. A second dose of fentanyl was available to any patient requiring further pain relief in the PARR, or acetaminophen if the pain occurred in the ambulatory surgery unit.

Patients were discharged from the hospital when they were alert and oriented, had stable vital signs, could ambulate (as appropriate for age) with minimal assistance, and could tolerate clear liquids with only minimal nausea and vomiting. Time of discharge from PARR, time of ambulation and time to discharge home from the ambulatory surgery unit were all recorded. Possible complications were assessed by history and physical examination in the postanaesthetic recovery room and outpatient short-stay recovery unit, as well as by followup telephone interviews done by the blinded observer the day following surgery. Inquiry was made as to the need for further pain medication and the time the child returned to his usual "bright and alert status" the day of surgery.

Student's $t$ test was used to compare differences between the two groups with regard to age, durations of anaesthesia and surgery, discharge times and time until oral analgesics were required; and the Mann-Whitney test was used to compare the pain scores. The number of patients in the two groups requiring supplemental fentanyl was compared by Fisher's exact test. ${ }^{\circ}$

\section{Results}

Patients in both groups were comparable with regards to age and the duration of both anaesthesia and surgery. There were no statistically significant differences in postoperative pain/discomfort scores, the requirement for supplemental parenteral analgesics in the recovery room, or the time to meet criteria for discharge (Table II).

Patients receiving a caudal block following anaesthetic induction but prior to the beginning of surgery were discharged $179( \pm 88)$ min following completion of surgery, while those who received a caudal block at the end of surgery were discharged after $189( \pm 75) \mathrm{min}$. The time until oral analgesics were required was similar for both groups; Group I at $96( \pm 40) \mathrm{min}$, and Group 2 at 105 $( \pm 55) \mathrm{min}$. There was no difference in the reported time to return to a normal "bright and alert" status at home 
TABLE II Age of patienıs, duration of anaesthesia and surgery, pain score, analgesic requirements and discharge time

\begin{tabular}{lcc}
\hline & $\begin{array}{l}\text { Group I } \\
(n=20)\end{array}$ & $\begin{array}{l}\text { Group 2 } \\
(n=20)\end{array}$ \\
\hline Age (mo)* & $55.5( \pm 33.0)$ & $56.4( \pm 24.5)$ \\
Duration of anaesthesia (min)* & $66.6( \pm 20.1)$ & $64.4( \pm 17.8)$ \\
Duration of surgery (min)* & $37.2( \pm 16.2)$ & $33.6( \pm 17.1)$ \\
Pain score in PARR (median) & 2 & 1 \\
Number of patients requiring fentanyl & $2(10 \%)$ & None \\
Discharge time (min)* & $179( \pm 88)$ & $189( \pm 75)$ \\
Time until oral analgesics requested $(\min )^{*}$ & $96( \pm 40)$ & $105( \pm 55)$ \\
\hline
\end{tabular}

$* \pm S D$.

among the two groups. There were no anaesthesia or block-related complications in any patient.

\section{Discussion}

The use of regional anaesthesia in children produces profound postoperative pain relief without the need for opioid medication and its attendant side effects. 1,3,4,6 Furthermore, the use of regional anaesthesia as an adjunct to light general anaesthesia may provide special advantages for children undergoing surgery as outpatients, in whom this technique is associated with decreased requirement of both opioid and non-opioid analgesics, more rapid arousal, and earlier ambulation and discharge. ${ }^{1,3,5}$ Furthermore, adjunctive regional anaesthesia performed prior to surgery may be expected to reduce the risk of reflex laryngospasm in response to surgical stimulation and thus obviate the need for tracheal intubation. ${ }^{7}$ Caudal blocks are the most useful and popular regional technique in current use in paediatric anaesthesia. ${ }^{4}$ Appropriate brief ambulatory procedures that are amenable to a combined caudal-light general anaesthesia technique include circumcision, hypospadias repair, anal surgery, orthopaedic procedures on the foot, as well as the procedures described in this study. These are among the most common surgical procedures performed in infants and children. The results of this study show that performance of a caudal block prior to the beginning of short surgical procedures does not result in a measurable decrease in the duration of postoperative analgesia compared with performing the block at the conclusion of surgery.

Our results support the prevailing clinical impression that the analgesic state of the child during the time he/she emerges from general anaesthesia is a key factor to the smoothness of the postoperative period. The two groups of patients that we studied had their blocks established before emergence from general anaesthesia. This may be the reason why the course of their recovery was similar.
Our conclusions are only applicable to procedures of short duration. The standard deviation of the duration of analgesia in our patients exceeded the mean duration of the surgical procedures, thus small differences (e.g., less than 20 minutes) between Groups 1 and 2 would not be easily detected. If the surgical procedure is anticipated to be long, exceeding one hour, then one might place the caudal block at the end of surgery, or, alternatively, to repeat the injection at the conclusion of surgery or place a catheter to allow reinjection.

We conclude that the decision to perform caudal block before or after brief surgical procedures should be based upon factors other than the anticipated duration of postoperative analgesia.

\section{References}

I Shandling B, Steward DJ. Regional analgesia for postoperative pain in pediatric outpatient surgery. J Pediatr Surg 1980; 15: 477-80.

2 Anderson $R, K r o g h K$. Pain as a major cause of postoperative nausea. Can Anaesth Soc J 1976; 23: 366.

3 Hannallah RS, Broadman LM, Belman AB, Abramowitz $M D$, Epsiein $B S$. Comparison of caudal and ilioinguinal/iliohypogastric nerve blocks for control of post-orchiopexy pain in pediatric ambulatory surgery. Anesthesiology 1987; 66: 832-4.

4 Wolf A, Valley RD, Fear DW, Roy WL, Lerman J. Bupivacaine for caudal analgesia in infants and children; the optimal effective concentration. Anesthesiology 1988; 69: 102-6.

5 Broadman $L M$. Regional anesthesia for the pediatric outpatient. Anesth Clin North Am 1987; 5: 53-72.

6 Aldrete JA, Krouli $K D$. A postanesthetic recovery score. Anesth Analg 1970; 49: 924-34.

7 Broadman $L M$, Hannallah RS, Belman AB et al. Postcircumcision analgesia - a prospective evaluation of subcutaneous ring block of the penis. Anesthesiology 1987; 67: $399-402$. 